\title{
The Effect of Sustained Stellate Ganglion Stimulation on Left Ventricular Contractility in the Dog
}

\author{
Hitoshi Kanda, Takashi Haneda, Jun Ikeda, Tetsuya \\ Hiramoto, Motoyuki Furuyama, Toshiaki Sakuma, \\ Kunio Shirato and Tamotsu Takishima \\ The First Department of Internal Medicine, Tohoku \\ University School of Medicine, Sendai 980
}

\begin{abstract}
Kanda, H., Haneda, T., Ikeda, J., Hiramoto, T., Furuyama, M., Sakuma, T., Shirato, K. and Takishima, T. The Effect of Sustained Stellate Ganglion Stimulation on Left Ventricular Contractility in the Dog. Tohoku J. exp. Med., 1988, $156(2), 135-148$ - Although a progressive reduction in left ventricular contractility during sustained left stellate ganglion stimulation has been well documented, there have been no reports on the contractile state after nerve stimulation. Left ventricular contractility after cessation of $60 \mathrm{~min}$ of electrical $(10 \mathrm{~V}, 10$ $\mathrm{Hz}, 1 \mathrm{msec}$ ) left stellate ganglion stimulation has been assessed in open chest dogs. Before and 15 min after stimulation, left ventricular contractility was evaluated by the end-systolic pressure-segment length relationship using ultrasonic crystals during a stepwise aortic constriction to increase left ventricular afterload. Restimulation of the left stellate ganglion was also performed $15 \mathrm{~min}$ after cessation of the first stimulation. After sustained left stellate ganglion stimulation, the end-systolic points shifted to the right from the control and the slope of multiple pressure-segment length coordinates significantly decreased (102.5 \pm 16.1 to $76.5 \pm$ $10.2 \mathrm{mmHg} / \mathrm{mm}$, mean \pm s.e., $p<0.05, n=5$ ), indicating a depression of left ventricular contractility. Increased left ventricular $\mathrm{dP} / \mathrm{dt} \max$ and norepinephrine level in the coronary sinus gradually returned to near base line during 60 min of stimulation. These reduced responses lasted for at least $15 \mathrm{~min}$ after cessation of stimulation. The myocardial norepinephrine content was reduced to $0.59 \pm 0.08$ (mean \pm S.E.) $\mathrm{ng} / \mathrm{mg}$ wet tissue from $0.90 \pm 0.15$ of the control level $(p<$ 0.05 ). These data suggested that left ventricular contractility decreased after sustained cardiac sympathetic nerve stimulation, probably due to norepinephrine reduction in the myocardium. - stellate ganglion stimulation; left ventricular contractility; myocardial norepinephrine; plasma norepinephrine
\end{abstract}

It has been generally observed that supramaximal stimulation of the sympathetic nerves to various organs rapidly induces the maximal response, but the responsiveness then diminishes progressively with time (Dearnaley and Geffin 1966/7; Folkow et al. 1967). This progressive reduction was observed in the

Received May 31, 1988; revision accepted for publication September 3, 1988.

Address for reprint: Tamotsu Takishima, M.D., the First Department of Internal Medicine, Tohoku University School of Medicine, 1-1 Seiryo-machi, Sendai 980, Japan. 
heart as well by Levy and Blattberg (Levy and Blattberg 1976). A rapid increase of right ventricular contractile force and norepinephrine overflow into the coronary sinus occurred and then diminished gradually over the next 10 min of supramaximal electrical stimulation. However, they did not measure left ventricular contractility directly and also did not refer to the contractile state after the cessation of nerve stimulation. If this progressive reduction in norepinephrine overflow is attributable to acute depletion of norepinephrine in the postganglionic sympathetic nerve terminals (Levy and Blattberg 1976), left ventricular contractility might decrease after cessation of sympathetic nerve stimulation. Since the functional capacity of the cardiac sympathetic nerve has not been fully elucidated, it is important to know whether the effect exist after stimulation or not.

In the present series of canine experiments, we applied 60 min of supramaximal left stellate ganglion stimulation which diminished left ventricular (LV) dP/ dt max response. After the cessation of stimulation, we compared the myocardial norepinephrine content and left ventricular contractile state with pre-stimulation values.

\section{Methods}

\section{General preparation}

Twenty three mongrel dogs weighing $12.5-23.0 \mathrm{~kg}$ were initially anesthetized with intravenous sodium pentobarbital $(30 \mathrm{mg} / \mathrm{kg})$. Thereafter the anesthetic was infused continuosuly $(5 \mathrm{mg} / \mathrm{kg} / \mathrm{hr})$ to maintain stable anesthesia during the experiments. Artificial ventilation was accomplished with a Harvard respirator with room air enriched by $100 \% \mathrm{O}_{2}$ and arterial blood oxygen saturation was kept within 95-99\%. Left ventricular pressure was measured with a catheter tip manometer with a fluid filled lumen (No. 8F, Millar Instruments, Houston, TX, USA) which was inserted into the ventricle through the femoral artery. A left sided thoracotomy was performed at the level of third and fourth intercostal space. The left stellate ganglion was carefully isolated and bipolar silver electrodes were placed at the left stellate ganglion and connected to a stimulator (MSR-3R, Nihon-Kohden, Tokyo). Both vagosympathetic trunks were cut at the neck $30 \mathrm{~min}$ before control measurements were made.

\section{Experimental protocol and measurements}

Preparation for evaluating left ventricular end-systolic pressure-segment length relationships by sustained left stellate ganglion stimulation.

In this group (Group $1 ; n=5$ ), a small incision in the pericardium was made and a pair of ultrasonic crystals was implanted intramyocardially in the mid portion of the left ventricular anterior free wall, parallel to their equator, $1.0-1.5 \mathrm{~cm}$ apart and at a depth of from 8 to $12 \mathrm{~mm}$. The leads were then connected to an ultrasonic dimension system (model 401, Schussler, San Diego, CA, USA). After implanting the crystals, the pericardium was sutured with care being taken not to diminish the original pericardial space. We also put a ligature around the descending aorta to produce an aortic constriction. In this group, end-systolic pressure-segment length $(\mathrm{P}-\mathrm{L})$ relationships were examined during aortic constriction and left stellate ganglion stimulation. To examine end-systolic P-L relationships, a P-L loop was constructed on a storage oscilloscope (5103N, Tektronix, Beaverton, OR, USA) during each cardiac cycle with the pressure signal from the micromanometer on the 
ordinate and the segment length from ultrasonic crystals on the abscissa.

Before stimulation, the aorta was constricted in a stepwise manner for about 5 sec to obtain the changes in the P-L loop. Then, the left stellate ganglion was stimulated for 60 min. Fifteen min after cessation of the stimulation, the aorta was again constricted to trace the P-L loops.

Study of left ventricular pressure and coronary sinus norepinephrine response to sustained left stellate ganglion stimulation

In this group (Group $2 ; n=5$ ), a No. $6 \mathrm{~F}$ catheter was inserted into the coronary sinus through the right jugular vein. After control recording of left ventricular pressure and its first derivative (left ventricular $\mathrm{d} \mathbf{P} / \mathrm{dt}$ ) and blood sampling for norepinephrine assay, the left stellate ganglion was electrically stimulated at an intensity of $10 \mathrm{~V}$, a frequency of 10 $\mathrm{Hz}$ and a duration of $1 \mathrm{msec}$ for $60 \mathrm{~min}$. Hemodynamic recordings were made after 1, 10, 30 and $60 \mathrm{~min}$ of stimulation and blood samples were taken after 1 and $60 \mathrm{~min}$ of stimulation. Fifteen min after cessation of stimulation, when parameters were stable, the recording and sampling were performed again. The left stellate ganglion was then restimulated in the same manner for $1 \mathrm{~min}$ while recording and samplings were repeated. We determined cornary sinus blood flow before and after each stimulation by the thermodilution method using a thermodilution catheter inserted into the coronary sinus from the right atrium.

Determination of plasma norepinephrine

Plasma norepinephrine assay was carried out with a modification of Renzini's original procedure within two weeks after sampling. Purification and condensation of plasma norepinephrine was performed with an alumina and Amberlite CG-50 ( $\mathrm{Na}^{+}$form) column system as reported by Valori and associates (Valori et al. 1970). The norepinephrine absorbed on the Amberlite resin was finally eluted with $1.2 \mathrm{ml}$ of $0.1 \mathrm{M}$ sodium tetraborate. The eluates from the Amberlite column were oxidized by the method of Valori and associates with minor modifications (Miura et al. 1977). 2-Mercaptoethanol $(0.05 \mathrm{ml}$ of $10 \%$ $(\mathrm{v} / \mathrm{v})$ in 25 percent formaldehyde solution) was used as a reducing agent 3 min after the start of oxidation. External standards of norepinephrine and epinephrine (5 to $10 \mathrm{ng}$ of each amine) and a reagent blank without amines were prepared in $1.2 \mathrm{ml}$ of sodium tetraborate$\mathrm{HCl}$ buffer, $\mathrm{pH} 7.0$, and oxidized as sample eluates. The oxidized mixture was left at room temperature for 60 to $120 \mathrm{~min}$ after oxidation. The fluorescence of the reaction mixture was then measured on a HITACHI Model MPF-4 (Tokyo) spectrophotometer in a high sensitivity cell assembly at two sets of excitation/emission wavelengths ( $410 / 490$ and $452 / 490 \mathrm{~nm})$ with an adequate slit system and sensitivity. The concentration of norepinephrine and epinephrine in the oxidized mixture was then compared by solving the equation proposed by Valori and associates (Valori et al. 1970),

$$
\begin{aligned}
& \mathrm{x}=(\mathrm{F} 2-\mathrm{yNE} 2) / \mathrm{E} 2 \\
& \mathrm{y}=[\mathrm{F} 1 \times(\mathrm{E} 2 / \mathrm{E} 1)-\mathrm{F} 2] /[\mathrm{NE} 1 \times(\mathrm{E} 2 / \mathrm{E} 1)-\mathrm{NE} 2],
\end{aligned}
$$

where $\mathrm{x}$ and $\mathrm{y}$ are the amounts (in pg) of epinephrine and norepinephrine in the samples; $F 1$ and F2 are fluorescence readings corrected for the blank values at $410 / 490$ and $452 / 490$ $\mathrm{nm}$, respectively and E1, E2, NE1 and NE2 are the fluorescence values for $1000 \mathrm{pg}$ of epinephrine and norepinephrine at $410 / 490$ and $452 / 490 \mathrm{~nm}$, respectively.

This method permitted accurate measurement of levels as low as 25 to $50 \mathrm{pg} / \mathrm{ml}$ per sample of plasma (Haneda et al. 1980).

Study of myocardial tissue norepinephrine measurement after sustained left stellate ganglion stimulation

Before and after left stellate ganglion stimulation, myocardial biopsy was performed in this group (Group $3 ; n=5$ ). An incision less than $30 \mathrm{~mm}$ in length was made in the pericardium and myocardial tissue was sampled from the mid portion of the left ventricular 
anterior free wall. The pericardium was then sutured loosely and left stellate ganglion stimulation was continued for another $60 \mathrm{~min}$. After completion of this stimulation, the pericardium was reopend and myocardial biopsy was performed again. We excised myocardial tissue from four different regions which were adjacent to the previous sampling site to avoid variance due to regional differences (Gordon et al. 1984). These specimens were bomogenized with $0.1 \mathrm{~N} \mathrm{HCl}$ at $4^{\circ} \mathrm{C}$ as soon as they were obtained and centrifuged at $4^{\circ} \mathrm{C}$ $(3000 \mathrm{rpm}$ for $10 \mathrm{~min})$. The supernatant was then kept at $-10^{\circ} \mathrm{C}$ until assay was performed. The assay for tissue norepinephrine was performed according to the method described above.

\section{Preparation for control studies}

To confirm the baseline stability of these experiments, measurements and sampling were performed twice at $75 \mathrm{~min}$ intervals in eight dogs without nerve stimulation; myocardial norepinephrine biopsy $(n=5)$ and P-L loop recording $(n=3)$ were repeated.

Results are expressed as mean \pm s.t. Significance was determined using the Student's $t$-test for paired data and the significance level was taken $p<0.05$.

\section{RESULTS}

As shown in Table 1, the trends in heart rate and left ventricular $\mathrm{dP} / \mathrm{dt} \max$ during sustained left stellate ganglion stimulation were similar in the 3 groups and there were no significant overall intergroup differences with respect to these parameters.

Changes in left ventricular end-systolic pressure-length relationships after sustained left stellate ganglion stimulation

Aortic constriction raised the left ventricular systolic pressure and left ventricular end-diastolic pressure immediately with the elongation of left ventricular end-diastolic length and left ventricular end-systolic length. The end-systolic point (left upper corner of each loop) moved upward to the right beat by beat during stepwise aortic constriction and the transition of the end-systolic points was linear in the early few beats as shown in Fig. 1A. Fifteen min after cessation of sustained left stellate ganglion stimulation, as shown in Fig. 1B, the end-systolic points shifted to the right side of the control points and the slope of

TABLE 1. Changes in heart rate and $L V d P / d t$ max on sustained left stellate ganglion stimulation in each group

\begin{tabular}{|c|c|c|c|c|c|c|c|c|}
\hline & \multicolumn{4}{|c|}{ Heart rate (beats/min) } & \multicolumn{4}{|c|}{$\mathrm{LV} \mathrm{dP} / \mathrm{dt} \max \left(\mathrm{mmHg}_{\mathrm{g}} / \mathrm{sec}\right)$} \\
\hline & Control & $1 \min$ & $60 \mathrm{~min}$ & After & Control & $1 \min$ & $60 \min$ & After \\
\hline $\begin{array}{l}\text { Group 1 } \\
\quad(n=5)\end{array}$ & $127 \pm 6$ & $141+9$ & $122 \pm 7$ & $116 \pm 6$ & $1925 \pm 145$ & $5200 \pm 395^{* *}$ & $2205 \pm 210$ & $1790 \pm 220$ \\
\hline $\begin{array}{l}\text { Group } 2 \\
\quad(n=5)\end{array}$ & $134 \pm 9$ & $145 \pm 4$ & $134 \pm 9$ & $132 \pm 12$ & $1855 \pm 120$ & $5600 \pm 380^{* *}$ & $2075 \pm 205$ & $1625 \pm 125$ \\
\hline $\begin{array}{l}\text { Group } 3 \\
(n=5)\end{array}$ & $130 \pm 8$ & $144 \pm 5$ & $134 \pm 6$ & $132 \pm 8$ & $2005 \pm 205$ & $5005 \pm 350^{* *}$ & $2250 \pm 210$ & $1855 \pm 140$ \\
\hline
\end{tabular}

Values are means \pm s.E. ${ }^{* *} p<0.01$ vs. control. 
A

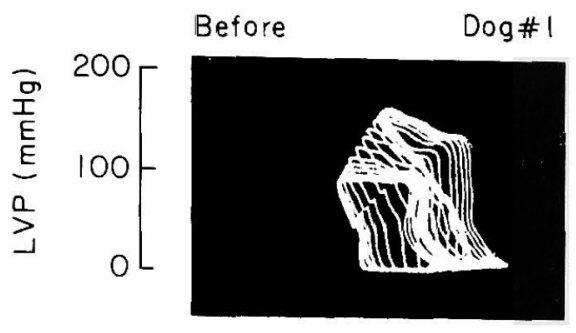

B

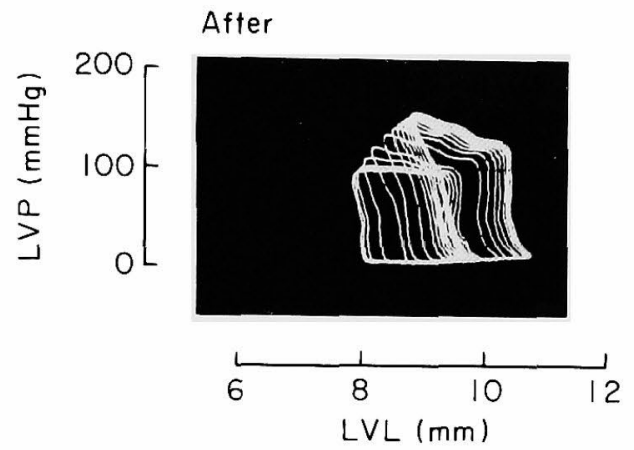

Fig. 1. Pressure-segment length (P-L) relationships during acute aortic constriction before left stellate ganglion stimulation (A) and $15 \mathrm{~min}$ after sustained left stellate ganglion stimulation (B). LVL, left ventricular segment length ; LVP, left ventricular pressure.

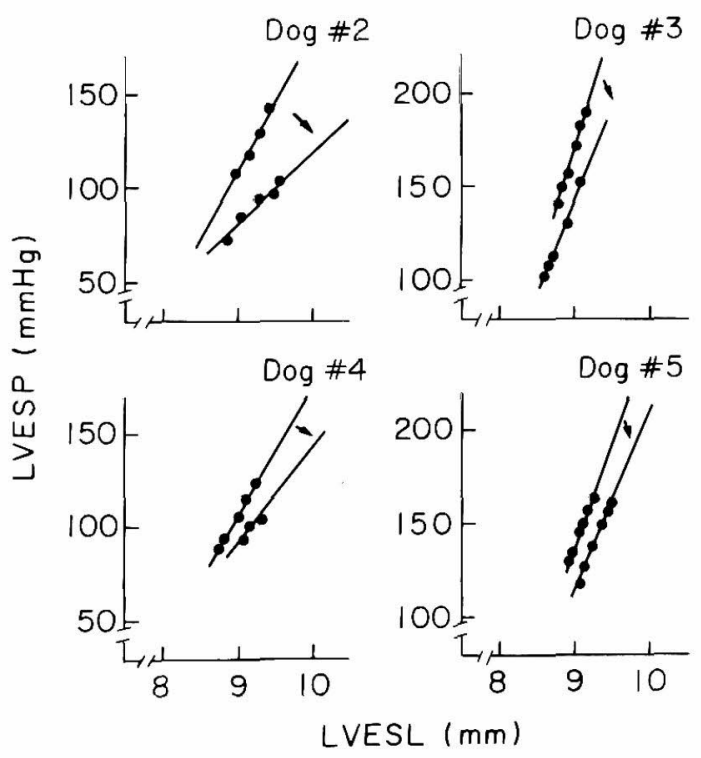

Fig. 2. Changes of the slope of multiple end-systolic pressure-segment length coordinates after sustained left stellate ganglion stimulation $(10 \mathrm{~V}, 10 \mathrm{~Hz}, 1$ $\mathrm{msec}$, for $60 \mathrm{~min}$ ) in other four dogs. $\mathbf{r}=0.99-1.00$ for eight lines. LVESL, left ventricular end-systolic segment length; LVSP, left ventricular systolic pressure. 
the multiple end-systolic P-L coordinates decreased compared with the control slope. The remaining other four dogs also showed similar changes (Fig. 2) ; that is as a whole, the slope of the multiple end-systolic P-L coordinates was significantly decreased after cessation of left stellate ganglion stimulation (control, $102.5 \pm 16.1 \mathrm{mmHg} / \mathrm{mm}$; after $60 \mathrm{~min}$ of left stellate ganglion stimulation, $76.5 \pm$ $10.2 \mathrm{mmHg} / \mathrm{mm}, p<0.05)$.

Time course of hemodynamics and plasma norepinephrine levels during left stellate ganglion stimulation

Hemodynamic changes on sustained left stellate ganglion stimulation are shown in Fig. 3. Heart rate did not significantly change during stimulation. Left ventricular systolic pressure was elevated through the first $10 \mathrm{~min}$ of stimulation but returned to the baseline level after 50-60 min of stimulation. In contrast, left ventricular end-diastolic pressure decreased after 1 min but returned to baseline thereafter. Coronary sinus blood flow was slightly increased at 1 min of stimulation but the inerement was not significant. The most notable change was observed in left ventricular $\mathrm{dP} / \mathrm{dt} \max$, which increased by $205 \pm 20 \%$ after $1 \mathrm{~min}$ of stimulation but then decreased gradually to near the control level by the end of left stellate ganglion stimulation.

The changes in plasma norepinephrine levels caused by sustained left stellate ganglion stimulation are also shown in Fig. 3. Although a small increment was observed in norepinephrine in the aorta at $1 \mathrm{~min}$ of stimulation (control, $152 \pm 54$
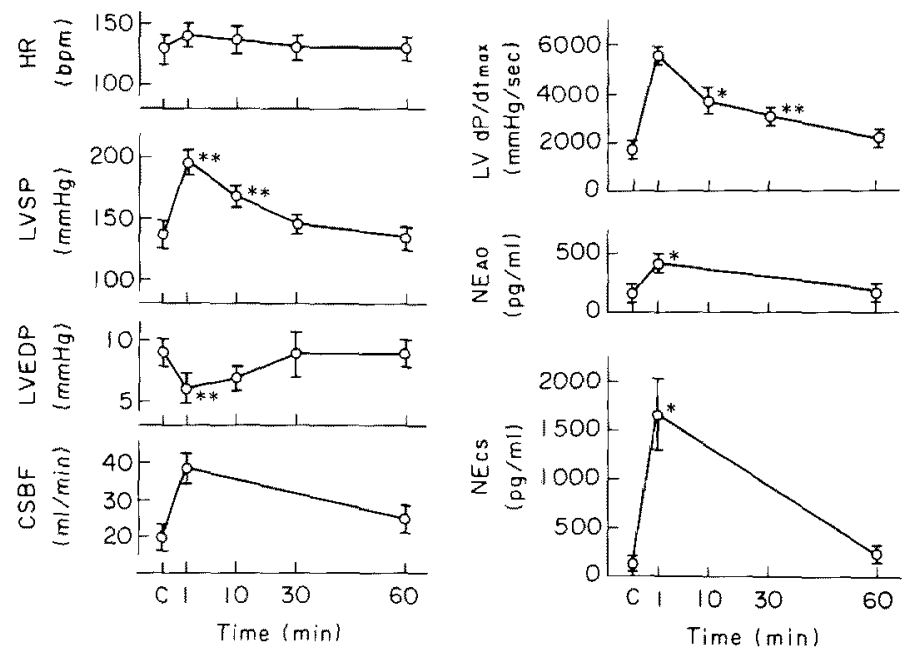

Fig. 3. Time course of hemodynamics and plasma norepinephrine (NE) levels during left stellate ganglion stimulation. Each point represents the mean \pm S.E. for five dogs. ${ }^{*} p<0.05,{ }^{* *} p<0.01 ; \mathrm{C}$, control; CSBF, coronary sinus blood flow; LVEDP, left ventricular end-diastolic pressure; LVSP, left ventricular systolic pressure; $\mathrm{NEAO}$, norepinephrine levels in the aorta; NEcs, norepinephrine levels in the coronary sinus. 
TABLE 2. Increases in hemodynamic parameters and plasma norepinephrine during 1 st and 2nd stimulation

\begin{tabular}{|c|c|c|c|c|c|c|}
\hline & $\begin{array}{c}\text { Ist } \\
\text { control }\end{array}$ & $\begin{array}{l}\text { Stim. } \\
1 \mathrm{~min}\end{array}$ & $\begin{array}{c}\text { 1st } \\
\text { change }\end{array}$ & $\begin{array}{l}\text { 2nd } \\
\text { control }\end{array}$ & $\begin{array}{l}\text { Stim. } \\
\text { I min }\end{array}$ & $\begin{array}{l}\text { 2nd } \\
\text { change }\end{array}$ \\
\hline $\begin{array}{l}\text { Heart rate } \\
\qquad \text { (beats } / \mathrm{min} \text { ) }\end{array}$ & $134 \pm 9$ & $145 \pm$ & $11 \pm$ & $131 \pm 13$ & $131 \pm 13$ & $-2 \pm 1$ \\
\hline $\begin{array}{l}\mathrm{CSBF} \\
(\mathrm{ml} / \mathrm{min})\end{array}$ & $20 \pm 4$ & $39 \pm$ & $19 \pm$ & $26 \pm$ & $38 \pm 7$ & $12 \pm$ \\
\hline$(\mathrm{mmHg})$ & $145 \pm 10$ & $190 \pm 13$ & $45 \pm 10$ & $139 \pm$ & $150 \pm 10$ & $11 \pm$ \\
\hline $\begin{array}{l}\text { LVEDP } \\
(\mathrm{mmHg})\end{array}$ & $10 \pm \quad 1$ & $7 \pm \quad 1$ & $-3 \pm$ & $12 \pm$ & $12 \pm 2$ & $0 \pm$ \\
\hline $\begin{array}{l}\mathrm{LV} \mathrm{dP} / \mathrm{dt} \max \\
(\mathrm{mmHg} / \mathrm{sec})\end{array}$ & $1855 \pm 120$ & $5600 \pm 380$ & $3365 \pm 355$ & $1625 \pm 170$ & $2160 \pm 359$ & $535 \pm 320^{*}$ \\
\hline NEAO $\quad(\mathrm{pg} / \mathrm{ml})$ & $152 \pm 54$ & $403 \pm 63$ & $251 \pm 64$ & $228 \pm 46$ & $247 \pm 30$ & $24 \pm 35^{*}$ \\
\hline$(\mathrm{pg} / \mathrm{ml})$ & $135 \pm 51$ & $1673 \pm 400$ & $1538 \pm 397$ & $191 \pm 34$ & $292 \pm 76$ & $101 \pm 57^{*}$ \\
\hline
\end{tabular}

Values are means \pm S.E. ${ }^{*} p<0.05$ vs. change in lst stimulation.

CSBF, coronary sinus blood flow; LVEDP, left ventricular end-diastolic pressure; LVSP, left ventricular systolic pressure; NEAO, plasma norepinephrine concentration in aortic blood; $\mathrm{NEcs}$, plasma norepinephrine concentration in coronary sinus blood.

$\mathrm{pg} / \mathrm{ml}$ vs. $403 \pm 63 \mathrm{pg} / \mathrm{ml}$ at $1 \mathrm{~min}, p<0.05)$, it had returned to the control value by the end of the stimulation $(228 \pm 46 \mathrm{pg} / \mathrm{ml})$. In contrast, the stimulation markedly increased norepinephrine levels in the coronary sinus. That is, at $1 \mathrm{~min}$ of stimulation, norepinephrine levels in the coronary sinus increased to $1673 \pm 400$ $\mathrm{pg} / \mathrm{ml}$ from the control level of $135 \pm 51 \mathrm{pg} / \mathrm{ml}(p<0.05)$. The increment decreased at the end of stimulation $(247 \pm 30 \mathrm{pg} / \mathrm{ml})$, but the value was still higher than that of the control $(p<0.05)$.
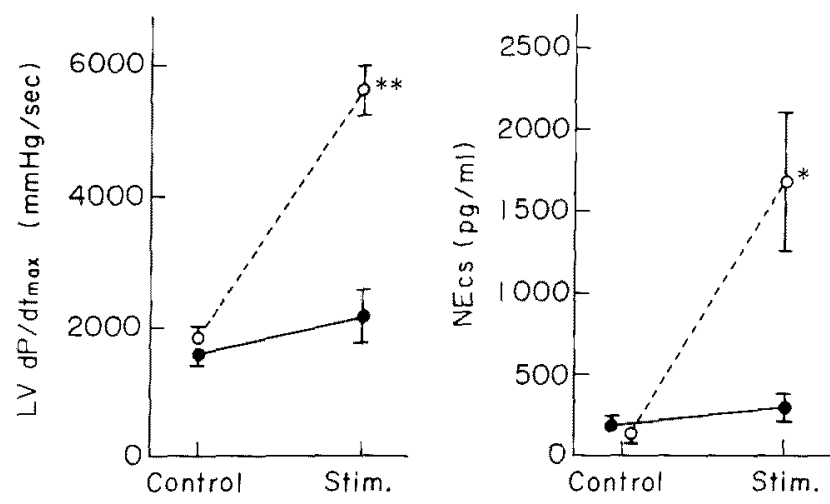

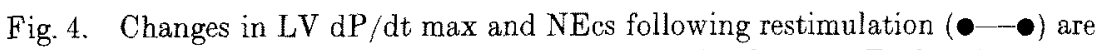
compared with those $(0 \cdots \cdots)$ due to the first stimulation. Each point represents the mean \pm s.e. for five dogs. ${ }^{*} p<0.05,{ }^{* *} p<0.01$, NEcs, norepinephrine levels in the coronary sinus. 
Fifteen min after cessation of sustained left stellate ganglion stimulation, the left stellate ganglion was restimulated for $1 \mathrm{~min}$. Changes in all hemodynamic parameters were smaller than those which occurred with the first stimulation (Table 2). Especially, increments in left ventricular $\mathrm{dP} / \mathrm{dt}$ max and norepinephrine levels in the coronary sinus on restimulation were significantly smaller than those on the first stimulation as shown in Fig. $4(535 \mathrm{mmHg} / \mathrm{sec}$ vs. 3365 $\mathrm{mmHg} / \mathrm{sec}, p<0.05 ; 101 \mathrm{pg} / \mathrm{ml}$ vs. $1538 \mathrm{pg} / \mathrm{ml}, p<0.05$, respectively).

Changes in left ventricular norepinephrine content after sustained left stellate ganglion stimulation

Fig. 5 shown norepinephrine content in the left ventricular anterior myocardial tissue before and after the sustained left stellate ganglion stimulation. Norepinephrine content was $0.91 \pm 0.15 \mathrm{ng} / \mathrm{mg}$ wet tissue before stimulation. After sustained left stellate ganglion stimulation, norepinephrine content significantly decreased to $0.59 \pm 0.08 \mathrm{ng} / \mathrm{mg}$ wet tissue $(p<0.01)$.

\section{Control studies}

We repeated myocardial biopsy or hemodynamic measurements at $75 \mathrm{~min}$ intervals without left stellate ganglion stimulation. There were no significant differences in myocardial norepinephrine content $(0.94 \pm 0.08 \mathrm{ng} / \mathrm{mg}$ wet tissue vs. $0.98 \pm 0.16 \mathrm{ng} / \mathrm{mg}$ wet tissue) or the slope of multiple end-systolic P-L coordinates $(106.7 \pm 10.7 \mathrm{mmHg} / \mathrm{mm}$ vs. $105.4 \pm 10.6 \mathrm{mmHg} / \mathrm{mm}$, n.s.). An example is shown in Fig. 6.

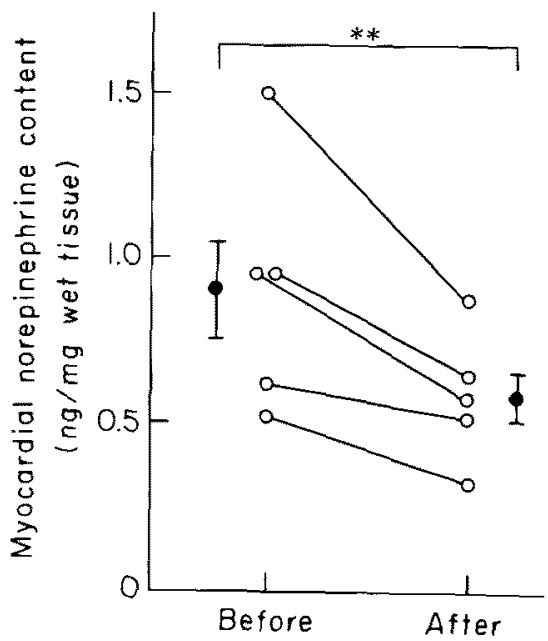

Fig. 5. Changes in left ventricular norepinephrine content by left stellate ganglion stimulation. Closed circles represent the mean \pm s.e. for five dogs. ${ }^{* *} p<0.01$. 

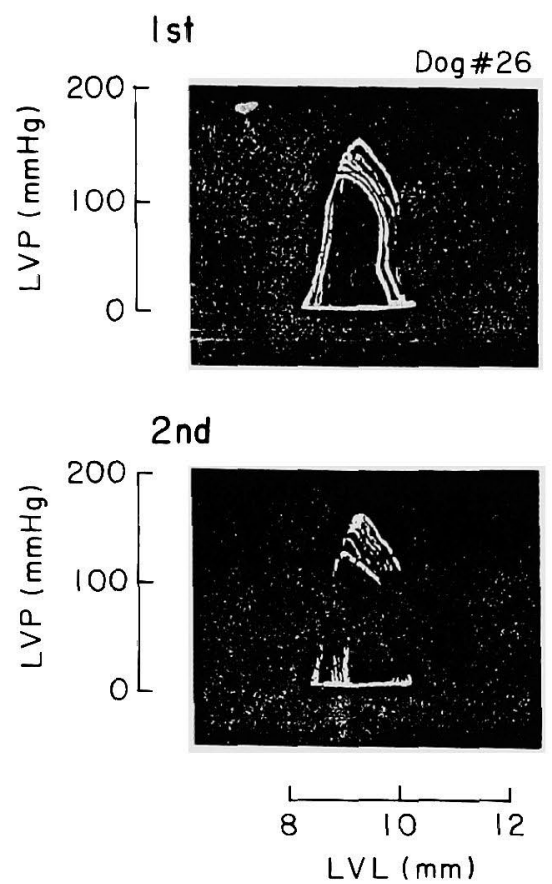

Fig. 6. An example of changes in the slope of multiple end-systolic pressuresegment length coordinates during acute aortic constriction after a $75 \mathrm{~min}$ interval without nerve stimulation. LVL, left ventricular segment length ; LVP, left ventricular pressure.

\section{Discussion}

Although the technique of electrical cardiac sympathetic nerve stimulation is widely used for experimental purposes, the contractile state after stimulation remains unclear. In the present experiment, we stimulated the left stellate ganglion at an intensity of $10 \mathrm{~V}$, a frequency of $10 \mathrm{~Hz}$ and a duration of $1 \mathrm{msec}$, which has been reported to be the condition of supramaximal stimulation (Yamaguchi et al. 1975). Further, we continued this stimulation for $60 \mathrm{~min}$. In the present study, we compared various parameters before stimulation with those 15 min after cessation of stimulation, where baseline levels were stable. Moreover, we restimulated the left stellate ganglion and compared the response of hemodynamic parameters between the first and second stimulations.

The effect of sustained left stellate ganglion stimulation on left ventricular contractility

The end-systolic pressure-volume relationship is thought to be the most reliable index for estimating left ventricular contractility (Suga and Sagawa 1974). We used the pressure-segment length rather than the pressure-volume relationship in the present study because Suga and Sagawa have shown a close 
positive correlation between ventricular diameter and volume at the end-systolic phase and end-diastolic phase in both isovolumic and ejection beats. Kanazawa et al reported that close positive correlation between left ventricular diameter and left ventricular segment length obtained as the same manner exists, and that the end-systolic P-I relationship is thus acceptable for estimating ventricular contractility (Suga and Sagawa 1974; Kanazawa et al. 1983; Crozatier et al. 1984). Aortic constriction has also been used as an experimental procedure for evaluating left ventricular contractility (Monroe et al. 1968; Crozatier et al. 1984). In the present study, as shown in Figs. 1 and 2, the end-systolic points shifted to the right compared with those of the control state and the slope of multiple end-systolic P-L coordinates decreased after sustained left stellate ganglion stimulation. This indicated, therefore, that left ventricular contractility decreased after cessation of $60 \mathrm{~min}$ of supramaximal left stellate ganglion stimulation and remained depressed for at least $15 \mathrm{~min}$ after cessation of the stimulation.

It should be studied whether time is a factor affecting these P-L relationships or not. In the present experiment, care was taken to maintain the depth of anesthesia by constant infusion of pentobarbital and to maintain hemodynamic stability to the extent possible, therefore norepinephrine levels in the aorta were kept within the physiological range throughout the experiments. Further, 3 dogs without nerve stimulation were used for the control study which compared the first measurement of the slope with the second measurement with a 75 min interval between the two. As shown in the results, the slope of the multiple end-systolic P-L coordinates did not decrease in these 3 dogs. From these facts, time is not a factor responsible for this reduction of the slope. Vagal excitation is not related to the present results because surgical vagotomy at both sides of the neck and decentralization of the left stellate ganglion was performed. And the damage to the sympathetic nerve fiber is also not related to these results, because we observed that the effect of sustained left stellate ganglion stimulation did not changee after 90-120 min interval (Ikeda et al. 1984). Since the heart rate was unchanged throughout the experiment, the reduction can not be attributed to a chronotropic effect. All of these facts lead us to conclude that prolonged left stellate ganglion stimulation itself decreases left ventricular contractility. The reduction in releasable norepinephrine at the nerve terminals seems to be the most probable cause of this phenomenon.

Time course of left ventricular $d P / d t$ max and norepinephrine levels in coronary sinus during sustained left stellate ganglion stimulation

In group 2, we observed the time course of the parameters during $60 \mathrm{~min}$ of left stellate ganglion stimulation. When the left stellate ganglion was stimulated at supramaximal intensity, left ventricular $\mathrm{dP} / \mathrm{dt}$ max increased by $205 \%$ after one min of stimulation without a significant increase in heart rate, and gradually decreased thereafter. The norepinephrine levels in the coronary sinus also in- 
creased by $1139 \%$ after one min of stimulation and returned to near baseline after 60 min of stimulation. Coronary sinus blood flow did not change significantly throughout the experiment. These results signify that norepinephrine overflow from the left ventricle was markedly reduced by $60 \mathrm{~min}$ of sympathetic nerve stimulation. If this reduction in norepinephrine overflow is due eigher to acceleration of norepinephrine uptake or to a negative feedback mechanism including the presynaptic alpha $a_{2}$-receptor, the norepinephrine overflow would be restored soon after a short period of cessation. However, markedly reduced responses in left ventricular $\mathrm{dP} / \mathrm{dt} \max$ and norepinephrine levels in the coronary sinus were similarly observed on restimulation, after the fifteen min rest interval. Levy and Blattberg found that progressive reduction of norepinephrine overflow was not modified by cocaine (norepinephrine reuptake blocker) or phenoxybenzamine

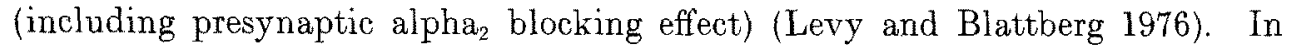
view of their results, such auto-regulatory mechanisms could not be the main cause for this phenomenon.

As to the reduction in the response of left ventricular $\mathrm{dP} / \mathrm{dt} \max$ to sustained nerve stimulation or restimulation, various other mechanisms can be postulated, for example, 1) desensitization of the beta adrenergic receptor (Lefkowitz and Williams 1978), 2) calcium-induced inhibition of adenyl cyclase and/or activation of cyclic nucleotides and phosphodiesterase (Tsien 1977),3) an accumulation of a product which could inhibit the beta-adrenergic response such as adenosine (Dobson 1978), 4) reversal of atropine-antagonism at the cholinergic receptors (Brown 1979), 5) an effect of histamine release (Gross et al. 1984). However, these mechanisms cannot account for the decrease in norepinephrine levels in the coronary sinus. Moreover, we observed that the effect of norepinephrine infusion on left ventricular $\mathrm{dP} / \mathrm{dt}$ max did not differ after $60 \mathrm{~min}$ of left stellate ganglion stimulation (unpublished data).

Accordingly, a reduction of norepinephrine in the myocardium, which continued for at least $15 \mathrm{~min}$ after cessation of $60 \mathrm{~min}$ of left stellate ganglion stimulation seems to be the most plausible explanation for decreased contractile response to restimulation.

Changes in myocardial norepinephrine content with sustained left stellate ganglion stimulation

The myocardial norepinephrine content obtained in this study corresponded closely to reported values (Pool et al. 1967). It is noteworthy that this value was reduced by $32.6 \pm 4.1 \%$ at the cessation of 60 min of left stellate ganglion stimulation. A time factor can be excluded from the present results, since myocardial norepinephrine content showed no significant change within $75 \mathrm{~min}$ in dogs without sustained left stellate ganglion stimulation. The reduction rate in the present study is much higher than that reported by Dearnaley and Geffin of a few percent reduction with 15 min of sympathetic nerve stimulation of the spleen 
(Dearnaley and Geffin 1966/7). This inconsistency could be due either to the difference in the organs or to the difference in stimulation time. According to a report by Harrison et al., administration of reserpine or guanethidine reduced myocardial norepinephrine content in the canine right atrium by about 35.6 or $35.8 \%$ respectively after two hr (Harrison et al. 1963). These reduction rates are compatible with those seen in the present study. Levy et al. hypothetized that myocardial norepinephrine at the nerve ending is stored in both relatively larger "storage" pools and smaller "secretary" pools and the norepinephrine which is stored in "secretary" vesicles only is releasable by sympathetic nerve stimulation (Levy and Blattberg 1976). Actually, norepinephrine released from the "secretary" pools would be largely taken up again in the "storage" pools during nerve stimulation and norepinephrine in the "storage" pools would not decrease significantly in a short time. Therefore, it is reasonable to assume that the rate of reduction of norepinephrine in the "secretary" pools was more profound than the rate of reduction of total myocardial norepinephrine content, and that the shortage of releasable norepinephrine may have occurred at the nerve terminals.

It remains controversial whether the reduction in releasable norepinephrine lowers left ventricular contractility. Several studies using isolated heart muscle have demonstrated no significant differences in the resting contractile state of the myocardium between normal and norepinephrine depleted specimens (Cairoli et al. 1962 ; Spann et al. 1966). Spann et al. suggested that norepinephrine depletion itself would not change the intrinsic contractile state of the myocardium (Spann et al. 1966). However, another report describes a positive relationship between myocardial norepinephrine depletion and defective myocardial contractility (Chidsey et al. 1966). Actually, the efferent sympathetic nerve is discharged each beat in situ (Felder and Thames 1981), so norepinephrine depletion seems to disturb the augmentation of contractility by sympathetic nerve excitation (Covell et al. 1966; Monroe et al. 1968). Thus, it is quite reasonable to assume that cardiac norepinephrine stores would play an important role in maintaining the cardiac contractile state in vivo.

In summary, we found that sustained cardiac sympathetic nerve stimulation induces a reduction in ventricular contractility which may be ascribed to a marked reduction of norepinephrine in the "secretary" pools in the myocardium. This phenomenon may be transient but it lasts at least $15 \mathrm{~min}$ following $60 \mathrm{~min}$ of supramaximal nerve stimulation. The present results provide a precise insight into the functional capacity of the cardiac sympathetic nerve system. In the present study, we used hearts with normal norepinephrine content. Therefore, in hearts with critically reduced norepinephrine content, this type of stimulation might more evidently affect left ventricular contractility.

\section{References}

1) Brown, J.W. (1979) Cholinergic inhibition of cathecholamine-stimulable cyclic AMP 
accumulation in murine atria. $J$. cyclic Nucleotide Res, 5, 423-433.

2) Cairoli, V.J., Reilly, J.F. \& Robberts, J. (1962) Effect of reserpine pretreatment on the response of isolated papillary muscle to epinephrine. Brit. J. Pharmacol., 18, $588-594$.

3) Chidsey, C.A., Sonnenblick, E.H., Morrow, A.G. \& Braunwald, E. (1966) Norepinephrine stores and contractile force of papillary muscle from the failing heart. Circulation, 33, 43-51.

4) Covell, J.W., Chidsey, C.A. \& Braunwald, E. (1966) Reduction of the cardiac response to postganglionic sympathetic nerve stimulation in experimental heart failure. Circulat. Res, 19, 51-56.

5) Crozatier, B., Caillet, D. \& Bical, O. (1984) Left ventricular adaptation to sustained pressure overload in the conscious dog. Circulat. Res., 54, 21-29.

6) Dearnaley, D.P. \& Geffin, L.B. (1966/7) Effect of nerve stimulation on the noradrenaline content of spleen. Proc. roy. Soc., 166, 303-315.

7) Dobson, J.G., Jr. (1978) Reduction by adenosine of the isoproterenol-induced increase in cyclic adenosine 3,5-monophosphate formation and glycogen phosphorylase activity in rat heart muscle. Circulat. Res., 43, 785-792.

8) Felder, R.B. \& Thames, M.D. (1981) The cardio-cardiac sympathetic reflex during coronary occlusion in anesthetized dogs. Circulat. Res., 48, 685-692.

9) Folkow, B., Haggendal, J. \& Lisander, B. (1967) Extent of release and elimination of norepinephrine at peripheral adrenergic nerve terminals. Acta physiol. scand., Suppl., 307, 1-38.

10) Gordon, L.P., DeMaster, E.G. \& Cohn, J.N. (1984) Regional differences in adrenergic function within the left ventricle. Amer. J. Physiol., 246, H824-H829.

11) Gross, S.S., Gou, Z.G., Levy, R., Bailey, W.H. \& Chenouda, A.A. (1984) Release of histamine by sympathetic nerve stimulation in the guinea pig heart and modulation of adrenergic response: A physiological role for cardiac histamine? Circulat. Res., 54, 516-526.

12) Haneda, T., Miura, Y., Arai, T., Nakajima, T., Miura, T., Honna, T., Kobayashi, K., Sakuma, H., Adachi, M., Miyazawa, K., Yoshinaga, K. \& Takishima, T. (1980) Norepinephrine levels in the coronary sinus in patients with cardiovascular disease at rest and during isometric handgrip exercise. Amer. Heart $J$., 100, 465-472.

13) Harrison, D.C., Chidsey, C.A., Goldman, R. \& Braunwald, E. (1963) Relationships between the release and tissue depletion of norepinephrine from the heart by guanethidine and reserpine. Circulat. Res., 12, 256-263.

14) Ikeda, J., Haneda, T., Kanda, H., Hiramoto, T., Furuyama, M., Shirato, K. \& Takishima, T. (1984) Does circulating norepinephrine affect the inotropic effect of the sympathetic nerve stimulation? Jap. Circulat. $J$., 48, 941. (Abstract)

15) Kanazawa, M., Shirato, K., Ishikawa, K., Nakajima, T., Haneda, T. \& Takishima, T' (1983) The effect of pericardium on the end-systolic pressure segment length relationship in canine left ventricle in acute volume overload. Circulat. Res., 68, 1290-1298.

16) Lefkowitz, R.J. \& Williams, L.T. (1978) Molecular mechanism of activation and desensitization of adenylate cyclase coupled beta-adrenergic receptors. Advanc. cyclic Nucleotide Res., 9, 1-17.

17) Levy, M.N. \& Blattberg, B. (1976) Progressive reduction in norepinephrine overflow during cardiac sympathetic nerve stimulation in anesthetized dog. Cardiovasc. Res., $10,549-555$.

18) Miura, Y., Campese, V., DeQuattro, V. \& Meijiner, D.J. (1977) Plasma cathecholamine via an improved fluorometric assay: Comparison with an enzymatic method. I. Lab. clin. Med., 89, 421-427.

19) Monroe, R.J., LaFarge, C.G., Gamble, W.J., Rosenthal, A. \& Honda, S. (1968) Left ventricular pressure-volume relation and performance as affected by sudden increase in deveioped pressure. Circulat. Res., 22, 333-344. 
20) Pool, P.E., Covell, J.W., Levitt, M., Gibb, J. \& Braunwald, E. (1967) Reduction on cardiac tyrosine hydroxylase activity in experimental congestive heart failure. Circulat. Res., 20, 349-353.

21) Spann, J.F., Sonnenblick, E.H., Caoper, T., Chidsey, C.A., Williams, V.L. \& Braunwald, E. (1966) Cardiac norepinephrine stores and contractile state of heart muscle. Circulat. Res., 19, 317-325.

22) Suga, H. \& Sagawa, K. (1974) Assesment of absolute volume from diameter of the intact canine left ventricular cavity. J. appl. Physiol., 36, 496-499.

23) Tsien, R.W. (1977) Cyclic AMP and contractile activity in heart. Advanc. cyclic Nucleotide Res., 8, 363-420.

24) Varoli, C., Brunori, C.A., Renzini, V. \& Gorea, L. (1970) Improved procedure for formation of epinephrine and norepinephrine fluorophors by the trihydroxyindole reaction. Analyt. Biochem, 33, 159-167.

25) Yamaguchi, N., Champlain, J. \& Nadeau, R. (1975) Correlation between the response of the heart to sympathetic stimulation and the release of endogenous cathecholamines into the coronary sinus of the dog. Circulat. Res., 36, 662-668. 